\title{
Changes in photosynthesis and carotenoid composition of pepper (Capsicum annuum L.) in response to low-light stress and low temperature combined with low-light stress
}

\author{
J.F. ZHANG ${ }^{* * *}$, J. LI*, J.M. XIE,*, J.H YU*, M.M. DAWUDA*,***, J. LYV*, Z.Q. TANG*, J. ZHANG*, \\ X.D. ZHANG*, and C.N. TANG* \\ College of Horticulture, Gansu Agricultural University, Yingmen Village, Anning District, 730070 Lanzhou, China* \\ Vegetable Institution of Gansu Academy of Agricultural Science, Anning District, 730070 Lanzhou, China** \\ Department of Horticulture, FoA, University for Development Studies, P. O. Box TL 1882, Tamale, Ghana**
}

\begin{abstract}
Light and temperature are two major factors for plant growth. Carotenoids are important photoprotective and lightharvesting pigments in photosynthetic organs. Therefore, this study explored photosynthesis and carotenoid-related metabolism under control (CK), low-light (L), and low-temperature and low-light (LL) conditions by using the pepper (Capsicum annuum L.) varieties Longjiao 5 and Hangjiao 4. We found the increased inhibition of plant growth and photosynthetic capacity under both L and LL stress. Meanwhile, carotenoid-related metabolic compounds accumulated in pepper showed different responses to the two stresses. Significantly, zeaxanthin contents were 6.69-8.88 times higher under LL than that of CK, $\alpha$-carotene contents were 0.9-2.1 times higher under L than that of CK, which may enhance the tolerance to LL and L. Our findings provide a foundation for further research on the molecular mechanism of carotenoid functions regarding $\mathrm{L}$ and LL tolerance by regulating photosynthesis.
\end{abstract}

Additional key words: chilling injury index; chlorophyll fluorescence; pigment content.

\section{Introduction}

Alterations in anatomical, physiological, and biochemical traits occur when plants acclimate to abiotic stress (Pengelly et al. 2010, Parida et al. 2016, Cao et al. 2017, Skupień et al. 2016, Arena and Vitale 2018, Sáez et al. 2018, Sahoo et al. 2018). Temperature and light, which are two key environmental factors for plants, are responsible for plant growth regulation, development, survival, and distribution (Kami et al. 2010, Barrero-Gil et al. 2016). In recent years, the occurrence of unfavorable weather conditions, such as fog, haze, continuous overcast and rainy days, and extremely low temperatures, has increased in China. As a result, low light $(\mathrm{L})$ or low temperature combined with low-light (LL) stress occur in many regions of northern China during mid-winter and has become a predominant limiting factor of off-season vegetable production in greenhouses (Ou et al. 2015, Yu et al. 2016, Zhu et al. 2017). L and LL are the most detrimental among stresses and consistently lead to a reduction in plant growth and crop production. Pepper, a thermophilous and heliophilic vegetable, originally from South America (McLeod et al. 1982), is strongly affected by L and LL at its growth stage.

The damage to plants caused by low light and low temperature originates from an imbalance between the light energy absorbed by photosystems and the energy

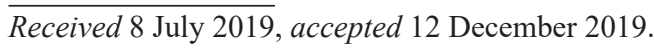

${ }^{+}$Corresponding author; phone: + 8613893335780 , e-mail: xiejianminggs@126.com

Abbreviations: Ant - antheraxanthin; Car - carotenoid content; Car T - sum of the ten carotenoids (neoxanthin, violaxanthin, antheraxanthin, lutein, zeathin, lutein-epoxide, lycopene, phytoene, $\alpha$-carotenoid, $\beta$-carotenoid); Car T/Car - the ten carotenoids/ carotenoid content; $\mathrm{Chl}$ - chlorophyll; $C_{\mathrm{i}}$ - intercellular $\mathrm{CO}_{2}$ concentration; $\mathrm{CI}$ - chilling injury; DPS - deepoxidation state defined as $(\mathrm{A}+\mathrm{Z}) /(\mathrm{V}+\mathrm{A}+\mathrm{Z}) ; E$ - transpiration rate; ETR - electron transport rate; $\mathrm{F}_{0}$ - minimal fluorescence; $\mathrm{F}_{\mathrm{m}}$ - maximum chlorophyll fluorescence; $\mathrm{F}_{\mathrm{v}}$ - variable chlorophyll fluorescence; $\mathrm{F}_{\mathrm{v}} / \mathrm{F}_{\mathrm{m}}$ - maximal photosystem quantum yield; $g_{\mathrm{s}}$ - stomatal conductance; HPLC - high-performance liquid chromatography; Lut - lutein; Lut-epoxide - lutein epoxide; Lyc - lycopene; Neo - neoxanthin; NPQ nonphotochemical quenching; Phy - phytoene; $P_{\mathrm{N}}$ - net photosynthetic rate; $\mathrm{q}_{\mathrm{L}}$ - photochemical quenching; $\mathrm{q}_{\mathrm{N}}-$ nonphotochemical quenching coefficient; $\mathrm{q}_{\mathrm{p}}$ - photochemical quenching coefficient; $\mathrm{V}+\mathrm{A}+\mathrm{Z}$ - sum of $\mathrm{V}$-cycle pigments (violaxanthin, antheraxanthin, and zeaxathin); Vio - violaxanthin; $\mathrm{Y}_{(\mathrm{II})}$ - actual quantum yield of PSII; $\mathrm{Y}_{(\mathrm{NO})}$ - quantum yield of nonregulated energy dissipation; $\mathrm{Y}_{(\mathrm{NPQ})}$ - quantum yield of regulated energy dissipation; Zea - zeaxathin; $\alpha$-Car $-\alpha$-carotenoids; $\beta$-Car $-\beta$-carotenoids.

Acknowledgements: The work was financially supported by the Scientific Research Start-Up Funds for Openly-Recruited Doctors (GAU-KYQD-2018-35), the State Special Fund for Agro-Scientific Research in the Public Interest (201203002), National Key Research and Development Program of China (2016YFD0201005), and Special Fund for Sci. \& Tech. Innovation and Development Guided by Gansu Province (2018ZX-02). The writers extremely acknowledge all the authors, the editors, and the reviewers for precious and valuable comments and suggestions, which have greatly improved the article.
} 
consumed by metabolic activities (Ruelland et al. 2009). In the study of Page et al (2012), the number of leaves and tillers in wheat decreased with decreasing light from 380 to $100 \mu \mathrm{mol}$ (photon) $\mathrm{m}^{-2} \mathrm{~s}^{-1}$, and wheat plants had long but minimally branched roots. In another study, the leaves of dicot Flaveria bidentis plants grown at a low light intensity [150 $\mu$ mol(photon) $\mathrm{m}^{-2} \mathrm{~s}^{-1}$ ] were $21 \%$ thinner than those grown at a medium light intensity [500 $\mu \mathrm{mol}$ (photon) $\mathrm{m}^{-2} \mathrm{~s}^{-1}$ ] and had $42 \%$ less mass per unit area (Pengelly et al. 2010). L also blocks photosynthetic electron transport and $\mathrm{F}_{\mathrm{v}} / \mathrm{F}_{\mathrm{m}}$, and the carbon assimilation enzyme activity of Chinese mini cabbage (Brassica pekinensis L.) (Hu et al. 2017). Moreover, low temperature can induce a membrane fluidity and water availability decline, irreversible reduction of photosynthetic rate, and impairments of PSII activity (Hikosaka et al. 2006).

Carotenoids (Car), a large group of natural pigments, play two vital roles in photosynthesis, namely, as light harvesting and photoprotection pigments due to their function as light acceptor and capability to protect photosynthetic organisms from oxidative damages by dissipating excess energy (Sies and Stahl 1995, Stahl and Sies 2003, Demmig-Adams and Adams 2006). Researchers have performed numerous studies on the Car compositions in plants, and most of them have contributed to the knowledge on the relationships between the formation of fruit color and Car contents (Daood and Biacs 2005, Perkins-Veazie et al. 2006, Giacalone et al. 2010, Guzman et al. 2010, Serrano et al. 2010, Wahyuni et al. 2011, Enfissi et al. 2017). However, studies on the influence of $\mathrm{L}$ on Car compositions are limited. In a previous work (McElroy et al. 2006), the amounts of zeaxanthin (Zea) and antheraxanthin (Ant) of creeping bentgrass decreased from 5.1 and $34 \mu \mathrm{g} \mathrm{g}^{-1}$ to 9 and $0.6 \mu \mathrm{g} \mathrm{g}^{-1}$, respectively, while violaxanthin (Vio), lutein (Lut), and lutein-5,6-epoxide (Lut-epoxide) increased after $24 \mathrm{~h}$ and then decreased from 24 to $168 \mathrm{~h}$ when transferred from high-irradiance to lowirradiance conditions. Notably, Lut was the predominant substance regardless of irradiance (McElroy et al. 2006). Another study showed that the amount of Zea in big tooth maple in shaded area was lower than that in unshaded areas, but the xanthophyll pigment pool was unchanged (Bowen-O'Connor et al. 2013).

Overall, many studies have reported on the influence of low light or low temperature alone on plant seedlings (Ogweno et al. 2009, Sui et al. 2012, Zhu et al. 2017, Megha et al. 2018, Lu et al. 2019), but only a few focused on the effects of LL, which is similar to the environment in greenhouses during winter-spring days. In particular, the Car composition in plants, especially in pepper leaves, under L and LL has not been reported. Our previous study examined the relationship between total Car content and tolerance to L or LL in pepper seedlings (Xie et al. 2010), but it still remains unclear which carotenoid compositions exert effect. Based on our preliminary experiments, we choose two varieties of pepper - Longjiao 5 and Hangjiao 4, which exhibited the most significant differences in the tolerance to low light and low temperature combined with low light. The present study aims to investigate the changes in photosynthetic pigments, photosynthetic properties, chlorophyll (Chl) fluorescence characteristics, and the core carotenoid-related metabolic compounds in response to normal temperature and light (CK), L, and LL. Our findings could provide a basis for further research on the molecular mechanism of chilling and weak light stress tolerance in pepper leaves and a theoretical basis for the breeding of pepper that is tolerant to L and LL.

\section{Materials and methods}

Plant material and growth conditions: Pepper (Capsicum annuum. L) seeds of Longjiao 5 (L5) and Hangjiao 4 (H4), obtained from the Gansu Academy of Agricultural Science and Tianshui Shenzhou Lvpeng Agricultural Technology Company, were soaked in water at $55^{\circ} \mathrm{C}$ with constant stirring for $30 \mathrm{~min}$ and then immersed in tap water for another $4 \mathrm{~h}$. The seeds were germinated on a moist towel saturated with tap water in a climate incubator at a temperature of $28^{\circ} \mathrm{C}$ in the dark for 3-4 d. Two seeds with radicle of the same size were transplanted into a black, plastic nutritive pot $(9 \times 9 \mathrm{~cm})$ containing seedling substrate (peat:vermiculite, 2:1) and grown in the Gansu Agricultural University greenhouse $\left(36^{\circ} 05^{\prime} 39.86 " \mathrm{~N}, 103^{\circ} 42^{\prime} 31.09^{\prime \prime} \mathrm{E}\right)$ with regular water and fertilizer management under the following conditions: a temperature of $28 / 18^{\circ} \mathrm{C}$ (day/ night), a 12-h photoperiod, a PPFD of $300 \mu \mathrm{mol}($ photon) $\mathrm{m}^{-2} \mathrm{~s}^{-1}$ and a relative humidity of $65-70 \%$.

Stress treatments: The uniform seedlings that reached the stage of seven fully expanded leaves were subjected to $\mathrm{L}$ and LL stress. The seedlings were transferred to a growth chamber (RDN-400E-4, Zhejiang, China). Temperature was set at $28 / 18^{\circ} \mathrm{C}$ (day/night) and PPFD of $300 \mu \mathrm{mol}$ (photon) $\mathrm{m}^{-2} \mathrm{~s}^{-1}(\mathrm{CK}), 28 / 18^{\circ} \mathrm{C}$ (day/night) and PPFD of $100 \mu \mathrm{mol} \mathrm{m}^{-2} \mathrm{~s}^{-1}(\mathrm{~L})$, and $15 / 5^{\circ} \mathrm{C}$ (day/night) and PPFD of $100 \mu \mathrm{mol} \mathrm{m}^{-2} \mathrm{~s}^{-1}$ (LL). The seedlings at different treatments were exposed to an average relative humidity of $65-70 \%$, a $12-\mathrm{h}$ photoperiod, and kept under the same water and fertilizer management.

The functional leaves (third-fourth fully expanded leaves) were collected for measurements after $20 \mathrm{~d}$. For each treatment, three replicates were performed, and each replicate included 60 pots of seedlings.

Morphological parameters: On the $20^{\text {th }}$ day of treatments, the height, stem diameter, leaf number, shoot and root fresh mass, shoot and root dry mass, and seedling index of varieties L5 and H4 were analyzed. The seedling index was calculated using the following formula: (stem diameter/height + root $\mathrm{DM} /$ shoot $\mathrm{DM}) \times \mathrm{DM}$, where total dry mass - DM, root dry mass - root DM, and shoot dry mass - shoot DM.

Assessment of chilling injury index and dry mass: The chilling injury (CI) index, representing the chilling tolerance, was assessed according to Semeniuk et al. (1986) with some modification after $20 \mathrm{~d}$ in darkness at $4{ }^{\circ} \mathrm{C}$. All the pepper leaves were assessed using the following CI grades (each variety had three replicates of 15 plants): $t=0$, no damage; $t=1$, leaf margin slightly 
dehydrated; $t=2$, leaf margin severely dehydrated; $t=3$, leaf margin severely dehydrated and several dark spots; $t=4$, leaf severely dehydrated with dehydrated patches and partial leaf shrinkage; and $t=5$, whole leaf dehydration and wilting. Following formula was used to calculate the CI of each seedling: $\mathrm{CI}=(\Sigma n \times t) /(N \times T)$, where $n$ is the grade of one leaf, $t$ is the leaf number of one grade, $N$ is the highest grade of one seedling, and $T$ is the total number of grades of one seedling. On the $20^{\text {th }}$ day of L and LL treatment, the samples were divided into shoots and roots, kept in oven at $80^{\circ} \mathrm{C}$ until they reached a constant mass, and then weighed.

Photosynthetic pigment contents: The pigment contents, including chlorophyll (Chl) $a$, Chl $b$, Chl $(a+b)$, and total carotenoid (Car) were determined according to $\mathrm{Hu}$ et al. (2015). Fresh pepper leaf samples (0.5 g) were immersed in $10 \mathrm{~mL}$ of $80 \%$ acetone for $48 \mathrm{~h}$ until the leaves became white. Then, the supernatant was assayed at absorbances of 645,663 , and $445 \mathrm{~nm}$ using an ultraviolet spectrophotometer (TU-1900, Beijing, China).

Chl fluorescence parameters were measured in pepper seedlings with Imaging-PAM fluorometer (Walz, Germany). After being stored in darkness at room temperature for $30 \mathrm{~min}$, the third youngest pepper leaf was selected for the measurement of parameters and three areas of one leaf were chosen. First, the minimal fluorescence $\left(\mathrm{F}_{0}\right)$ was recorded after illumination of the leaf with a measuring light, maximum $\mathrm{Chl}$ fluorescence $\left(\mathrm{F}_{\mathrm{m}}\right)$ was obtained after a saturation pulse, the variable Chl fluorescence $\left(\mathrm{F}_{\mathrm{v}}\right)$ was defined as $F_{m}-F_{0}$, and the maximum photochemical efficiency was calculated as $\mathrm{F}_{\mathrm{v}} / \mathrm{F}_{\mathrm{m}}$ (Krause and Weis 2003). The photochemical quenching coefficient ( $\left.q_{p}\right)$, nonphotochemical quenching coefficient $\left(\mathrm{q}_{\mathrm{N}}\right)$, nonphotochemical quenching (NPQ), photochemical quenching $\left(\mathrm{q}_{\mathrm{L}}\right)$, electron transport rate (ETR), energy allocated for photochemical reactions $\left[\mathrm{Y}_{(\mathrm{II})}\right]$, fraction of absorbed photon energy heat dissipated $\left[\mathrm{Y}_{(\mathrm{NO})}\right]$, and excess energy $\left[\mathrm{Y}_{(\mathrm{NPQ})}\right]$ were determined by kinetics curves of the saturation pulses applied after $320 \mathrm{~s}$ of illumination at $81 \mu \mathrm{mol}$ (photon) $\mathrm{m}^{-2} \mathrm{~s}^{-1}$ with a 20 -s interval (Kramer et al. 2004). Light curves were plotted using the relative measure of the apparent ETR at different PARs. The operation and data processing were evaluated using Imagining Win v. 2.46i software.

Photosynthetic parameters: The stomatal conductance $\left(g_{\mathrm{s}}\right)$, intercellular $\mathrm{CO}_{2}$ concentration $\left(C_{\mathrm{i}}\right)$, transpiration rate $(E)$, and net photosynthetic rate $\left(P_{\mathrm{N}}\right)$ of the third fully expanded leaves were measured with a portable photosynthesis system (CIRAS-2, PP-systems, UK) after treatment for $0,5,15$, and $20 \mathrm{~d}$. The instrument was deployed at a PPFD of $800 \mu \mathrm{mol} \mathrm{m} \mathrm{m}^{-2} \mathrm{~s}^{-1}$, a relative humidity of $75 \%$, an atmospheric $\mathrm{CO}_{2}$ concentration of 380-390 $\mu \mathrm{mol} \mathrm{mol}^{-1}$ and at room temperature. Data were recorded after steady values were reached.

Car-related metabolic compounds: Three replicates of $2 \mathrm{~g}$ of fresh pepper leaves lyophilized with liquid nitrogen were prepared for Car determination. The carotenoids were extracted and quantified according to Li et al. (2017), the ten carotenoid compositions were ultrasonically extracted using $16 \mathrm{ml}$ of acetone:ethyl acetate $(\mathrm{v} / \mathrm{v}, 1: 2)$ and passed through a $0.22-\mu \mathrm{m}$ millipore membrane. Waters 2695 HPLC (Waters, Milford, MA, USA) equipped with a Waters 2489 absorbance ultraviolet detector (45 nm) was used to quantify Neo, Vio, Ant, Lut, Zea, Lut-epoxide, lycopene, phytoene, $\alpha$-Car, and $\beta$-Car. The mobile phase consisted of acetonitrile (A), water (B), methyl tert-butyl ether:methanol (v/v, 1:1) (C), and ethyl acetate (D). $20 \mu \mathrm{L}$ of extract was injected into the HPLC system at a flow rate of $1 \mathrm{~mL} \mathrm{~min}^{-1}$. HPLC analysis was performed using a Welch ultimate column $X B-C 30(5 \mu \mathrm{m}, 250 \times 4.6 \mathrm{~mm}$ in diameter) under $30^{\circ} \mathrm{C}$.

Data analysis: The values used in figures and tables are the means of three replicates, and error bars represent the standard deviation of three independent experiments. The data were analyzed by one-way analysis of variance (ANOVA) to compare the means of different levels in the same treatment, including variance homogeneity. Duncan's multiple range test was used to assess the significance of the mean difference between treatments $(P<0.05)$. All statistical analyses were carried out using SPSS 19.0. All figures were created in Origin v. 8.5 and Adobe Photoshop CS 6 .

\section{Results}

Morphological parameters and chilling index: The seedlings under CK and L flowered when treated for 10-15 d and after 15-20 d, however, no flowers were observed under LL. The changes of height, stem diameter, leaf number, fresh mass, dry mass, and seedling index of L5 and H4 under stresses were analyzed (Table 1S, supplement). Compared with $\mathrm{CK}$, among the six parameters, the values of stem diameter, dry mass, and seedling index declined significantly by $15.3,22.9$, and $26.9 \%$, respectively, in L5 under L, while no significant changes were observed in any of those parameters of H4. Moreover, when treated with LL, the values of all those six parameters of L5 decreased by $10.8,11.0,28.6,29.5,31.3$, and $48.1 \%$, respectively, as for $\mathrm{H} 4$, the values of stem diameter, leaf number, fresh mass, dry mass, and seedling index decreased significantly by $22.7,25.0,35.7,27.0$, and $40.0 \%$, respectively, and the height slightly increased.

The statistical results showed that the CI of 0.841 in $\mathrm{H} 4$ was markedly higher than the CI of 0.453 in L5. As shown in Fig. 1, both varieties displayed irreversible damage and all leaves severely wilted, curved, and exhibited brown blotches. Specifically, all the leaves of the H4 seedlings turned yellow or brown, and stems of almost all seedlings were dehydrated, withered, and lodged from the root base. However, most leaves of L5 remained green and the stem remained upright, just only a few stems were lodged from the $3^{\text {rd }}$ to $4^{\text {th }}$ blades.

Photosynthetic pigment contents: Fig. 2 shows the concentration of photosynthetic pigments varying with the 
treatments $(\mathrm{CK}, \mathrm{L}$, and LL) in pepper seedlings of both cultivars. The Chl $a$ (Fig. $2 A$ ), Chl $b$ (Fig. $2 B), \mathrm{Chl}(a+b)$ (Fig. 2C), and total Car (Fig. 2D) contents were significantly lower in the L and LL treatments than that in CK. L lowered Chl $a$, Chl $b$, Chl $(a+b)$, and Car contents by 6.0 and $8.5 \%, 7.5$ and $6.1 \%, 6.3$ and $7.8 \%$, and 17.1 and $1.6 \%$ in $\mathrm{L} 5$ and $\mathrm{H} 4$, respectively. Under LL, the Chl $a$, Chl $b$, $\mathrm{Chl}(a+b)$, and Car contents all dramatically decreased by

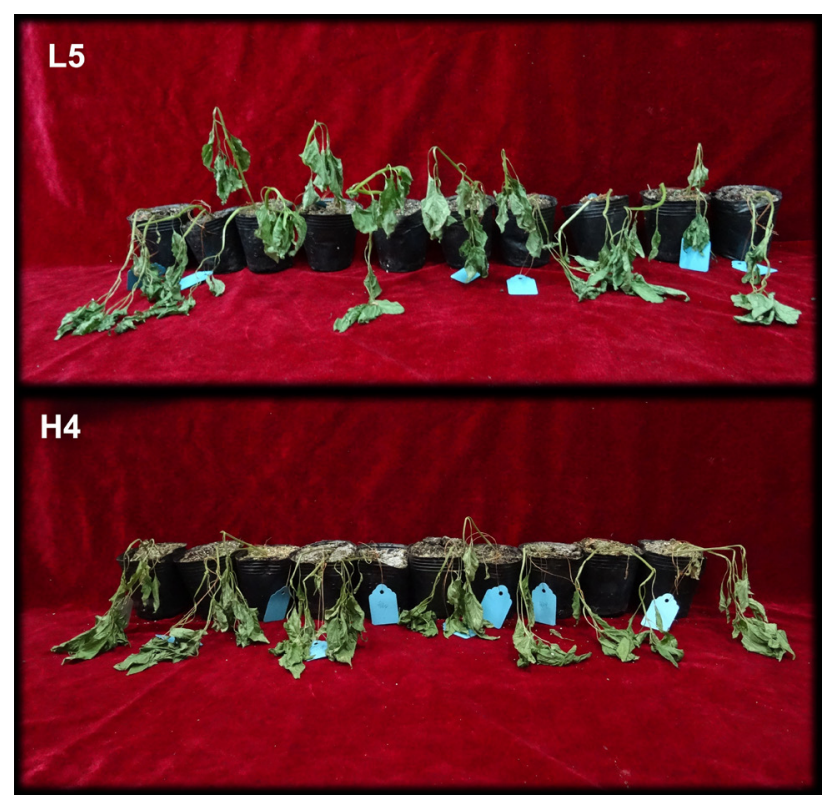

Fig. 1. Seedlings of L5 (Longjiao 5) and H4 (Hangjiao 4) treated for $20 \mathrm{~d}$ under low temperature and dark $\left(4 / 4^{\circ} \mathrm{C}\right.$, day/night temperature). The chilling injury (CI) was calculated. Data are the means of three independent replicates with 30 seedlings.
$23.2,33.7,26.2$, and $29.4 \%$ in L5 and by $31.1,29.8,30.7$, and $27.1 \%$ in $\mathrm{H} 4$ pepper, respectively.

Photosynthetic gas-exchange parameters, including $E$, $g_{\mathrm{s}}, P_{\mathrm{N}}$, and $C_{\mathrm{i}}$, were measured in the third fully expanded leaves on days $0,5,10,15$, and 20 after treatment (Fig. 3). Under L, the $E$ (Fig. $3 A$ ), $g_{\mathrm{s}}$ (Fig. $3 B$ ), and $P_{\mathrm{N}}$ (Fig. $3 C$ ) of L5 dramatically declined and then increased with values ranging from 4.80 to $3.75 \mathrm{mmol} \mathrm{m}^{-2} \mathrm{~s}^{-1}, 267.3$ to 273.7 mmol m${ }^{-2} \mathrm{~s}^{-1}$, and 8.83 to $8.70 \mu \mathrm{mol} \mathrm{m}^{-2} \mathrm{~s}^{-1}$, respectively. Moreover, the $E$ and $P_{\mathrm{N}}$ values were clearly lower at all time points after treatment compared with CK. Although $g_{\mathrm{s}}$ was higher after day 20, no significant differences were observed. By contrast, $C_{\mathrm{i}}$ (Fig. $3 D$ ) increased from 202.0 to $299.3 \mu \mathrm{mol} \mathrm{m}^{-2} \mathrm{~s}^{-1}$ and then declined to $223.3 \mu \mathrm{mol}$ $\mathrm{m}^{-2} \mathrm{~s}^{-1}$, showing significant differences between day 0 and 5,10 , and 15 . In $\mathrm{H} 4, E$ significantly increased and then decreased to the minimum value of $3.88 \mathrm{mmol} \mathrm{m}^{-2} \mathrm{~s}^{-1}$, representing a $14.3 \%$ reduction after $20 \mathrm{~d}$. However, the $g_{\mathrm{s}}$ values obtained on 5,15 , and $20 \mathrm{~d}$ were much higher than those of CK and the highest $g_{\mathrm{s}}$ of $417.3 \mathrm{mmol} \mathrm{m}^{-2} \mathrm{~s}^{-1}$ was reached after $15 \mathrm{~d}(66.9 \%$ increase compared to the value obtained on day 0 ). The $P_{\mathrm{N}}$ values significantly declined by $19.6,30.3,17.8$, and $12.9 \%$ after treatment for $5,10,15$, and $20 \mathrm{~d}$, respectively. On the contrary, the $C_{\mathrm{i}}$ values significantly increased by $30.1,52.9,67.5$, and $43.4 \%$, respectively.

Under LL, both L5 and H4 exhibited significant rapid decreases in $E$ (Fig. $3 A, F), g_{\mathrm{s}}$ (Fig. $3 B, G$ ), and $P_{\mathrm{N}}$ (Fig. $3 C, H$ ) every $5 \mathrm{~d}$ of the treatment. The lowest values were $0.61 \mathrm{mmol} \mathrm{m}^{-2} \mathrm{~s}^{-1}, 27.3 \mathrm{mmol} \mathrm{m}^{-2} \mathrm{~s}^{-1}$, and $0.47 \mu \mathrm{mol}$ $\mathrm{m}^{-2} \mathrm{~s}^{-1}$ for L5, which represented decrements of 87.3 , 89.8 , and $94.7 \%$, respectively. In variety $\mathrm{H} 4$, the lowest values were $0.32 \mathrm{mmol} \mathrm{m}^{-2} \mathrm{~s}^{-1}, 13.7 \mathrm{mmol} \mathrm{m} \mathrm{m}^{-2}$, and

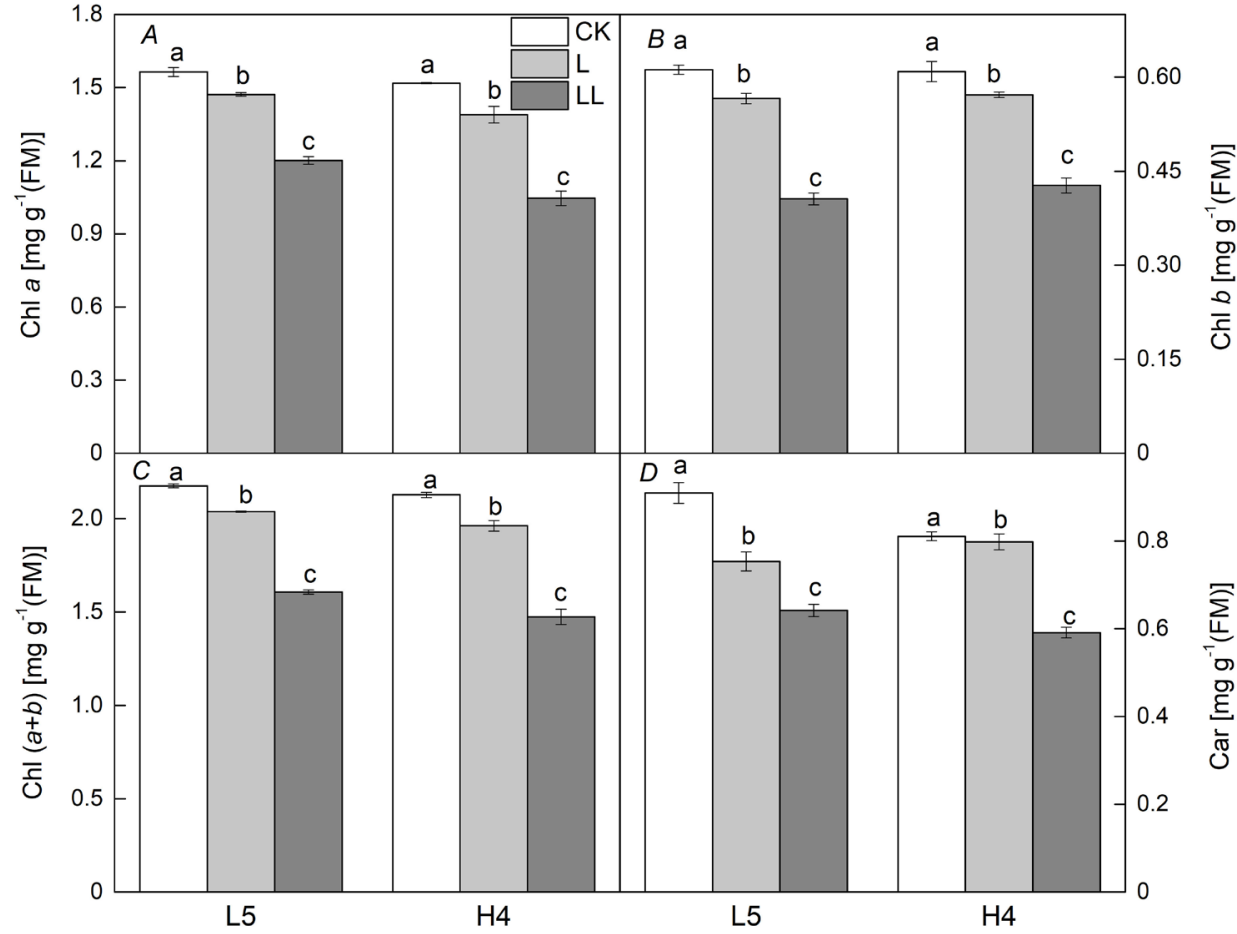

Fig. 2. Changes in photosynthetic pigment accumulation in the leaves of cultivars L5 (Longjiao 5) and H4 (Hangjiao 4) under different treatments: CK (normal temperature and light, $28 / 18^{\circ} \mathrm{C}$ and $300 \mu \mathrm{mol} \mathrm{m} \mathrm{m}^{-2} \mathrm{~s}^{-1}$ ), L (low light, $28 / 18^{\circ} \mathrm{C}$ and $100 \mu \mathrm{mol}$ $\mathrm{m}^{-2} \mathrm{~s}^{-1}$ ), and LL (low temperature combined with low light, $15 / 5^{\circ} \mathrm{C}$ and $100 \mu \mathrm{mol} \mathrm{m} \mathrm{m}^{-2} \mathrm{~s}^{-1}$ ). (A) Chl $a$-chlorophyll $a$ content; (B) Chl $b$ - chlorophyll $b$ content; (C) Chl $(a+b)$ - total chlorophyll content; (D) Car - carotenoid content. Data are means \pm SD $(n=3)$, and significant differences (Duncan's test of oneway $A N O V A, P<0.05)$ between different treatment days are indicated by different letters. 


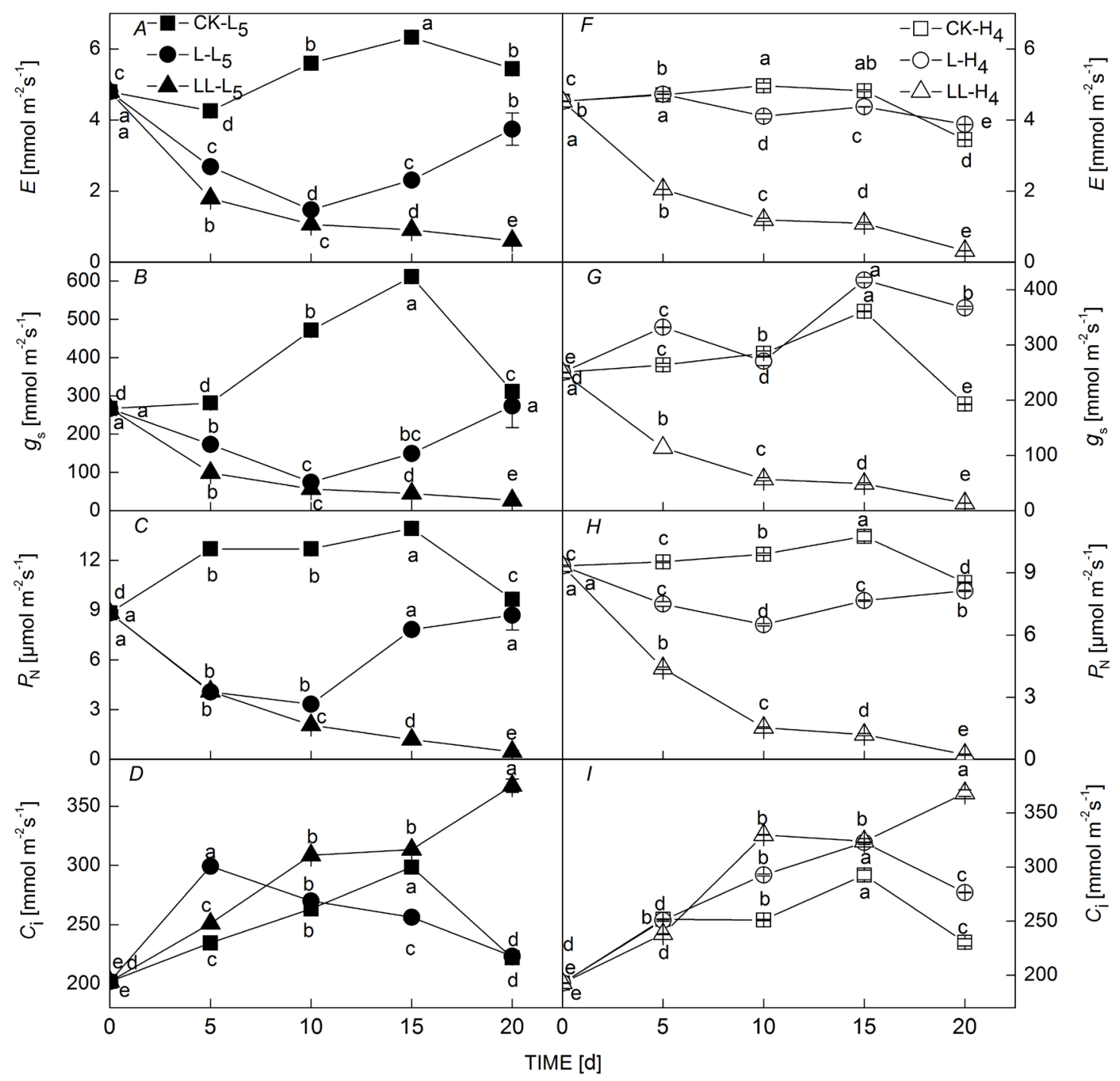

Fig. 3. Changes in photosynthetic gas exchange in the leaves of cultivars L5 (Longjiao 5) and H4 (Hangjiao 4) under different treatments: $\mathrm{CK}$ (normal temperature and light, $28 / 18^{\circ} \mathrm{C}$ and $300 \mu \mathrm{mol} \mathrm{m}^{-2} \mathrm{~s}^{-1}$ ), $\mathrm{L}$ (low light, $28 / 18^{\circ} \mathrm{C}$ and $100 \mu \mathrm{mol} \mathrm{m}^{-2} \mathrm{~s}^{-1}$ ), and LL (low temperature and low light, $15 / 5^{\circ} \mathrm{C}$ and $\left.100 \mu \mathrm{mol} \mathrm{m} \mathrm{m}^{-1}\right) .(A, F) E$ - transpiration; $(B, G) g_{\mathrm{s}}$ - stomatal conductance; $(C, H) P_{\mathrm{N}}-$ net photosynthetic rate; $(D, I) C_{\mathrm{i}}$ - intercellular $\mathrm{CO}_{2}$ concentration. $(A-D)$ - cultivar L5, $(F-I)$ - cultivar H4. Data are means $\pm \mathrm{SD}(n=3)$, and significant differences (Duncan's test of one-way ANOVA, $P<0.05$ ) between different treatment days are indicated by different letters.

$0.23 \mu \mathrm{mol} \mathrm{m} \mathrm{m}^{-2} \mathrm{~s}^{-1}$, which showed considerably more drastic reductions of $92.9,94.5$, and $97.5 \%$, respectively, when compared to L5. Nevertheless, the $C_{\mathrm{i}}$ values in both varieties increased from 202.0 to $367.3 \mu \mathrm{mol} \mathrm{m} \mathrm{m}^{-2} \mathrm{~s}^{-1}$ (81.8\% increase) in L5 (Fig. $3 D$ ) and from 192.7 to 368.3 $\mu \mathrm{mol} \mathrm{m} \mathrm{s}^{-2} \mathrm{~s}^{-1}(91.1 \%$ increase) in H4 (Fig. $3 I$ ). Statistically significant increments were detected between the periods before and after treatment.

Chl fluorescence parameters: The effects of L and LL on photosynthetic capacity were measured after 20 d. Figs. 4 and 5 showed that $F_{v} / F_{m}$ and ETR slightly increased under $\mathrm{L}$ in $\mathrm{H} 4$ but slightly decreased in L 5 compared with CK. However, they both dramatically decreased under the LL treatment and more drastic reductions were observed in H4 compared to L5, which is in agreement with the data listed in Table $1 \mathrm{~S}$.

The $\mathrm{q}_{\mathrm{N}}$ and NPQ of pepper seedlings exposed to $\mathrm{L}$ and LL were higher than those of CK seedlings, these increments in $\mathrm{q}_{\mathrm{N}}$ differed significantly between the three treatments in L5. The values were 4.9 and $29.0 \%$ higher for $\mathrm{q}_{\mathrm{N}}$ and 22.0 and $128.9 \%$ higher for NPQ in $\mathrm{H} 4$ under $\mathrm{L}$ and LL, respectively, compared with CK. By contrast, $\mathrm{q}_{\mathrm{P}}$ and $\mathrm{q}_{\mathrm{L}}$ exhibited opposite tendencies, namely, the results listed in Table 1S illustrate that $\mathrm{L}$ and LL caused a significant decrease, expressing larger reduction under LL. In addition, two stresses reduced the efficiency of $Y_{(I I)}$ in all pepper seedlings but increased $\mathrm{Y}_{(\mathrm{NPQ})}$. A larger reduction in $\mathrm{Y}_{(\mathrm{II})}$ or increase in $\mathrm{Y}_{(\mathrm{NPQ})}$ was found in the seedlings grown under LL compared to those grown under L. The $\mathrm{Y}_{(\mathrm{NO})}$ values in all treatments remained nearly unchanged (Fig. 6). 
Carotenoid-related metabolic compounds: The concentrations of Car compounds in the pepper leaves of L5 (Fig. 7; Fig. 1S, supplement) and H4 (Fig. 8; Fig. 2S, supplement) varied in response to L and LL. The main Car in the two varieties were Vio, Neo, Lut, Phy, $\alpha$-Car, and $\beta$-Car (concentration $>10 \mu \mathrm{g} \mathrm{g}^{-1}$ ), but Ant, Zea, and Lutepoxide were detected in small amounts (concentration $<1 \mu \mathrm{g} \mathrm{g}^{-1}$ ) under L. These results are in accordance with those for LL, except for Zea, which significantly increased 100 -fold.

By contrast, the concentrations of Neo, Vio, Lut, Lyc, Phy, and $\beta$-Car in L5 pepper leaves treated under L and LL were considerably higher than those under CK; it increased by $109.5,63.3,104.5,5.9,99.6$, and $57.5 \%$ under

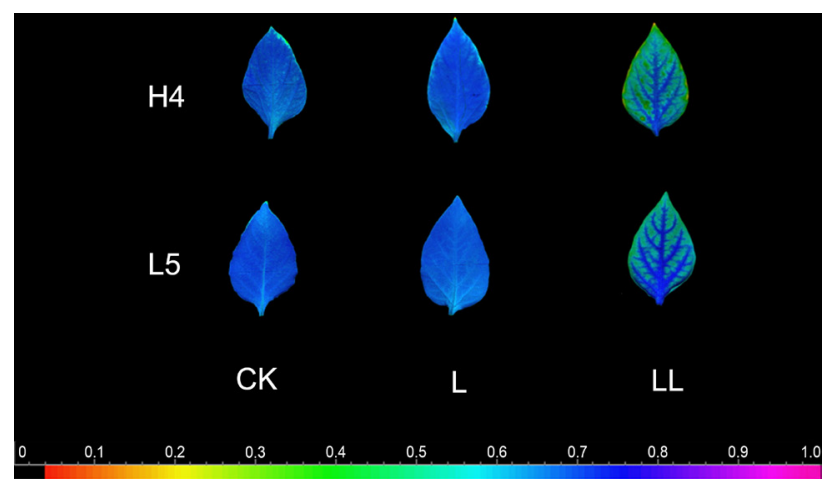

Fig. 4. Changes in the images of maximum quantum efficiency of photosystem II $\left(\mathrm{F}_{\mathrm{v}} / \mathrm{F}_{\mathrm{m}}\right)$ in the leaves of cultivars L5 (Longjiao 5) and $\mathrm{H} 4$ (Hangjiao 4) $20 \mathrm{~d}$ after treatment: $\mathrm{CK}$ (normal temperature and light, $28 / 18^{\circ} \mathrm{C}$ and $300 \mu \mathrm{mol} \mathrm{m}^{-2} \mathrm{~s}^{-1}$ ), L (low light, $28 / 18^{\circ} \mathrm{C}$ and $100 \mu \mathrm{mol} \mathrm{m} \mathrm{m}^{-2} \mathrm{~s}^{-1}$ ), and LL (low temperature combined with low light, $15 / 5^{\circ} \mathrm{C}$ and $\left.100 \mu \mathrm{mol} \mathrm{m}^{-2} \mathrm{~s}^{-1}\right)$. The fluorescence images of $F_{\mathrm{v}} / \mathrm{F}_{\mathrm{m}}$ are given in false colors that represent the absolute values of the ratio ranging from 0 (black) to 1.0 (purple).

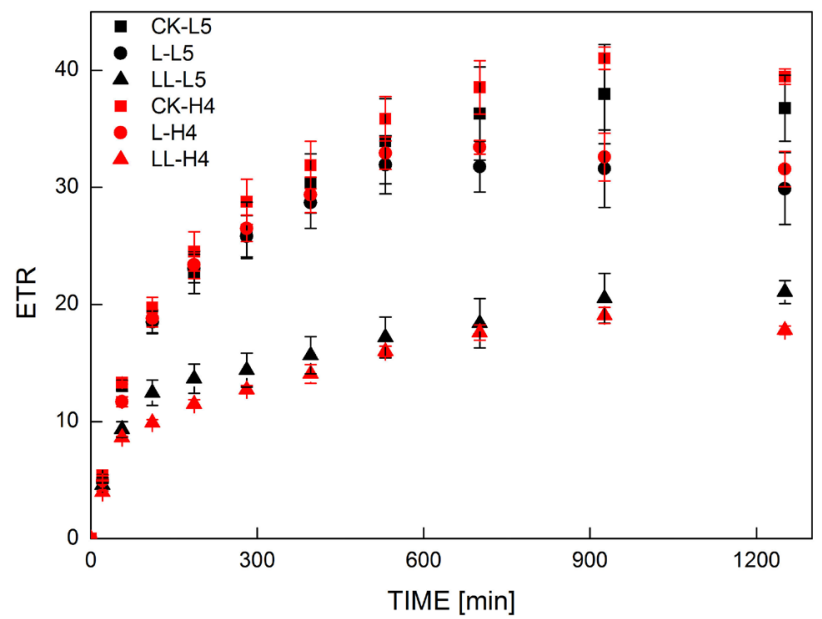

Fig. 5. Changes in the electron transport rate (ETR) in the leaves of cultivars L5 (Longjiao 5) and H4 (Hangjiao 4) $20 \mathrm{~d}$ after treatment: $\mathrm{CK}$ (normal temperature and light, $28 / 18^{\circ} \mathrm{C}$ and $300 \mu \mathrm{mol} \mathrm{m} \mathrm{m}^{-2} \mathrm{~s}^{-1}$ ), L (low light, $28 / 18^{\circ} \mathrm{C}$ and $100 \mu \mathrm{mol} \mathrm{m}{ }^{-2} \mathrm{~s}^{-1}$ ), and LL (low temperature combined with low light, $15 / 5^{\circ} \mathrm{C}$ and $100 \mu \mathrm{mol} \mathrm{m}^{-2} \mathrm{~s}^{-1}$ ). Each value (mean $\pm \mathrm{SD}$ ) represents the average of three independent experiments for each treatment.
L and $160.8,88.4,189.2,3.5,40.1$, and $103.7 \%$ under LL, respectively. However, Ant and Lut-epoxide significantly declined by 88.5 and $58.9 \%$ in $\mathrm{L}$ and 88.5 and $87.0 \%$ in LL, respectively. Notably, Zea, with a markedly enhanced concentration of $8.68 \mu \mathrm{g} \mathrm{g}^{-1}$, was considerably high under LL $\left(0.25 \mu \mathrm{g} \mathrm{g}^{-1}\right)$. Furthermore, the $\alpha$-Car was higher in response to $\mathrm{L}$ but showed no significant changes in LL. The increments in Vio under L and LL were associated with a substantial increase in Zea and directly contributed to significant differences in $\sum \mathrm{V}+\mathrm{A}+\mathrm{Z}$. The deepoxidation status (DPS), $(\mathrm{A}+\mathrm{Z}) /(\mathrm{V}+\mathrm{A}+\mathrm{Z})$, which was consistent with Zea enhancement, declined from 0.21 to 0.03 under $L$ but increased to 0.42 under LL. The total concentrations of the ten carotenoids (Car T) increased by 85.1 and $112.8 \%$ under $\mathrm{L}$ and LL, respectively, these in turn led to an increase in Car (Figs. 7, 1S).

In $\mathrm{H} 4$, the $\mathrm{L}$ and LL significantly altered the Neo, Vio, Zea, Lyc, and $\alpha$-Car contents, the concentration of $\beta$-Car significantly changed under LL but not under L, whereas Lut-epoxide showed significant changes under L but not under LL. Specifically, the Neo, Vio, Lut, Lutepoxide, Phy, $\alpha$-Car, and $\beta$-Car concentrations increased by $117.9,121.5,140.2,1272.4,4.4,95.1$, and $12.6 \%$, respectively. However, the others, such as Ant, Zea, and Lyc, decreased to varying degrees under L (i.e., 86.0, 76.9 , and $25.1 \%$, respectively). LL resulted in increments in Neo, Vio, Lut, Lut-epoxide, Zea, $\alpha$-Car, and $\beta$-Car concentrations of $150.1,136.5,159.8,20.7,888.5,47.5$, and $58.0 \%$, respectively. However, Ant, Lyc, and Phy declined by $84.4,19.9$, and $22.2 \%$, respectively. After L and LL stresses, $\mathrm{V}+\mathrm{A}+\mathrm{Z}$ increased from 6.54 to 11.70 and $18.03 \mu \mathrm{g} \mathrm{g}^{-1}$, respectively. These results are attributed to Vio and Zea, but not to Ant. A minimum DPS value of 0.02 was observed, but the $\alpha-C a r / \beta-C a r$ ratio (1.74) was the highest under L, which coincided with the results for L5. The total amounts of the ten carotenoids increased by 97.1 and $93.6 \%$ under L and LL, respectively, resulting in an increase in the Car T/Car (Figs. 8, 2S).

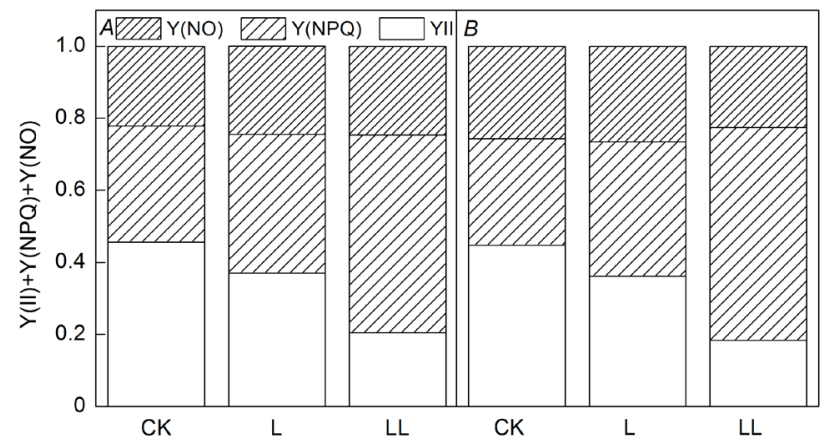

Fig. 6. Changes in the electron transport rate (ETR) in the leaves of cultivars L5 (Longjiao 5) and H4 (Hangjiao 4) $20 \mathrm{~d}$ after treatment: $\mathrm{CK}$ (normal temperature and light, $28 / 18^{\circ} \mathrm{C}$ and $300 \mu \mathrm{mol} \mathrm{m}^{-2} \mathrm{~s}^{-1}$ ), L (low light, $28 / 18^{\circ} \mathrm{C}$ and $100 \mu \mathrm{mol} \mathrm{m}^{-2} \mathrm{~s}^{-1}$ ), and LL (low temperature combined with low light, $15 / 5^{\circ} \mathrm{C}$ and $\left.100 \mu \mathrm{mol} \mathrm{m} \mathrm{m}^{-2} \mathrm{~s}^{-1}\right)$. (A) - cultivar L5, (B) - cultivar H4. Each value (mean $\pm \mathrm{SD}$ ) represents the average of three independent replicates for each treatment. 


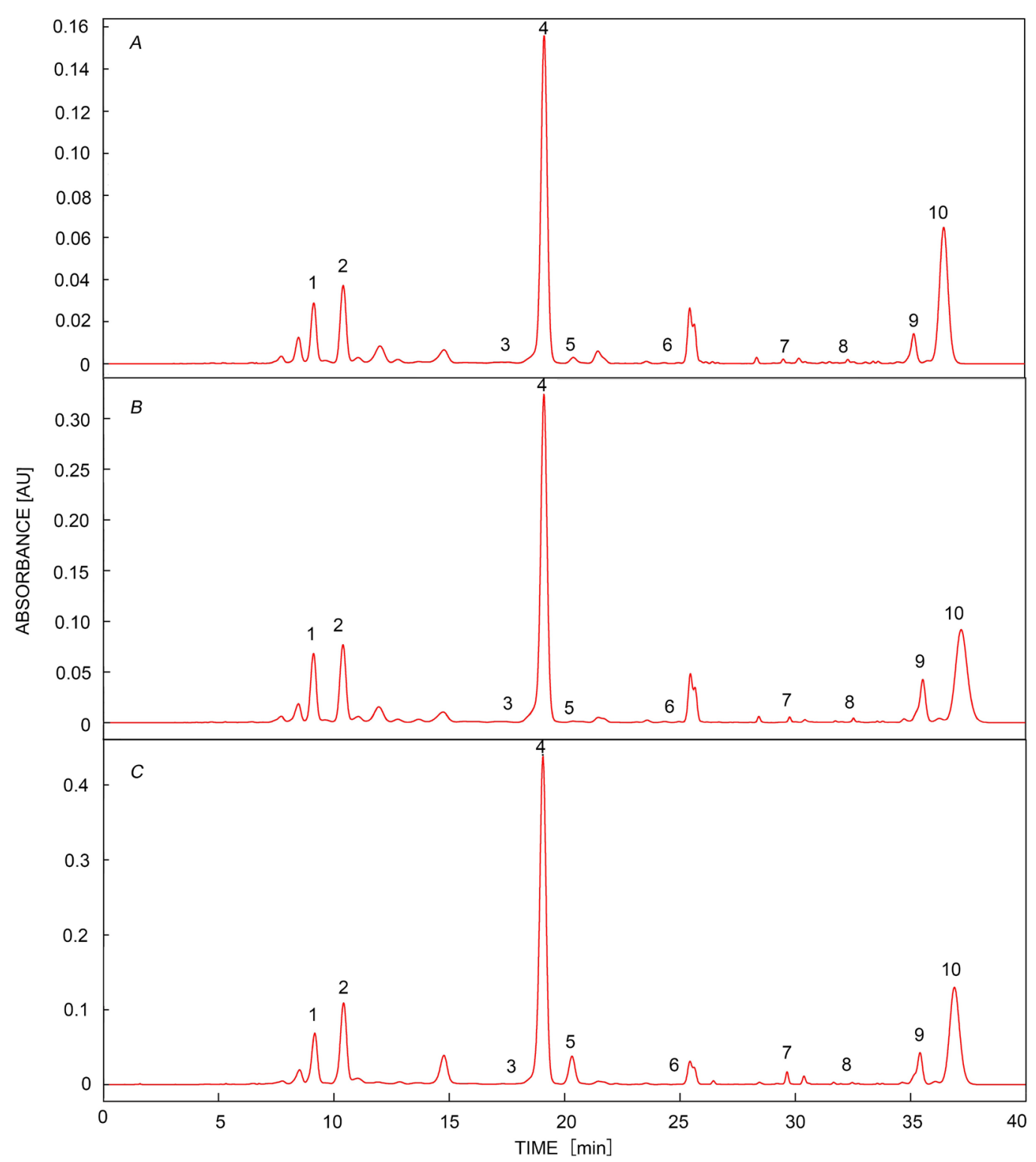

Fig. 7. Chromatograms of carotenoid compositions in L5 pepper leaves $20 \mathrm{~d}$ after treatment: $(A) \mathrm{CK}$ (normal temperature and light, $28 / 18^{\circ} \mathrm{C}$ and $300 \mu \mathrm{mol} \mathrm{m}^{-2} \mathrm{~s}^{-1}$ ); (B) L (low light, $28 / 18{ }^{\circ} \mathrm{C}$ and $100 \mu \mathrm{mol} \mathrm{m}^{-2} \mathrm{~s}^{-1}$ ), and (C) LL (low temperature combined with low light, $15 / 5^{\circ} \mathrm{C}$ and $\left.100 \mu \mathrm{mol} \mathrm{m}{ }^{-2} \mathrm{~s}^{-1}\right) .1$ - neoxanthin; 2 - violaxanthin; 3 - antheraxanthin; 4 - lutein; 5 - zeaxanthin; 6 - lutein epoxide; 7 - lycopene; 8 - phytoene; 9 - $\alpha$-carotene; and 10 - $\beta$-carotene.

\section{Discussion}

Light and temperature are two crucial factors that affect plants during their life cycle and are spatial and temporal indicators of appropriate conditions for development (Franklin et al. 2014). L and LL inhibit plant growth, interfere with physiological and biochemical processes (e.g., pigment synthesis and photosynthesis), and damage plant morphology and anatomy (Tattini et al. 2006, Seyfabadi et al. 2011, Greer and Weedon 2012, Caliandro et al. 2013, Li et al. 2015). In this study, LL decreased plant growth and leaf number, and the seedlings of two pepper varieties did not flower (Table 1S). These results are similar to those of other studies, which showed that compared with the control, the plant height, stem diameter, and fresh and dry mass display reductions of $36,23.6,65.1$, and $78.8 \%$, respectively, under LL in tomato seedlings (Lycopersicon esculentum Mill.) (Shu et al. 2016). However, our results differ from studies that concluded that heights and fresh mass are obviously higher under L than under CK, which is a consequence of shade avoidance response that is characterized by increased hypocotyl and stem caused by L with spectral signatures that differ from those under CK (Franklin 2008). Moreover, increased height and fresh mass are beneficial for pepper seedlings because these factors enable them to receive more light energy, which leads to slight inhibition and suggests that several plants have evolved the ability to survive and acclimate to shade 


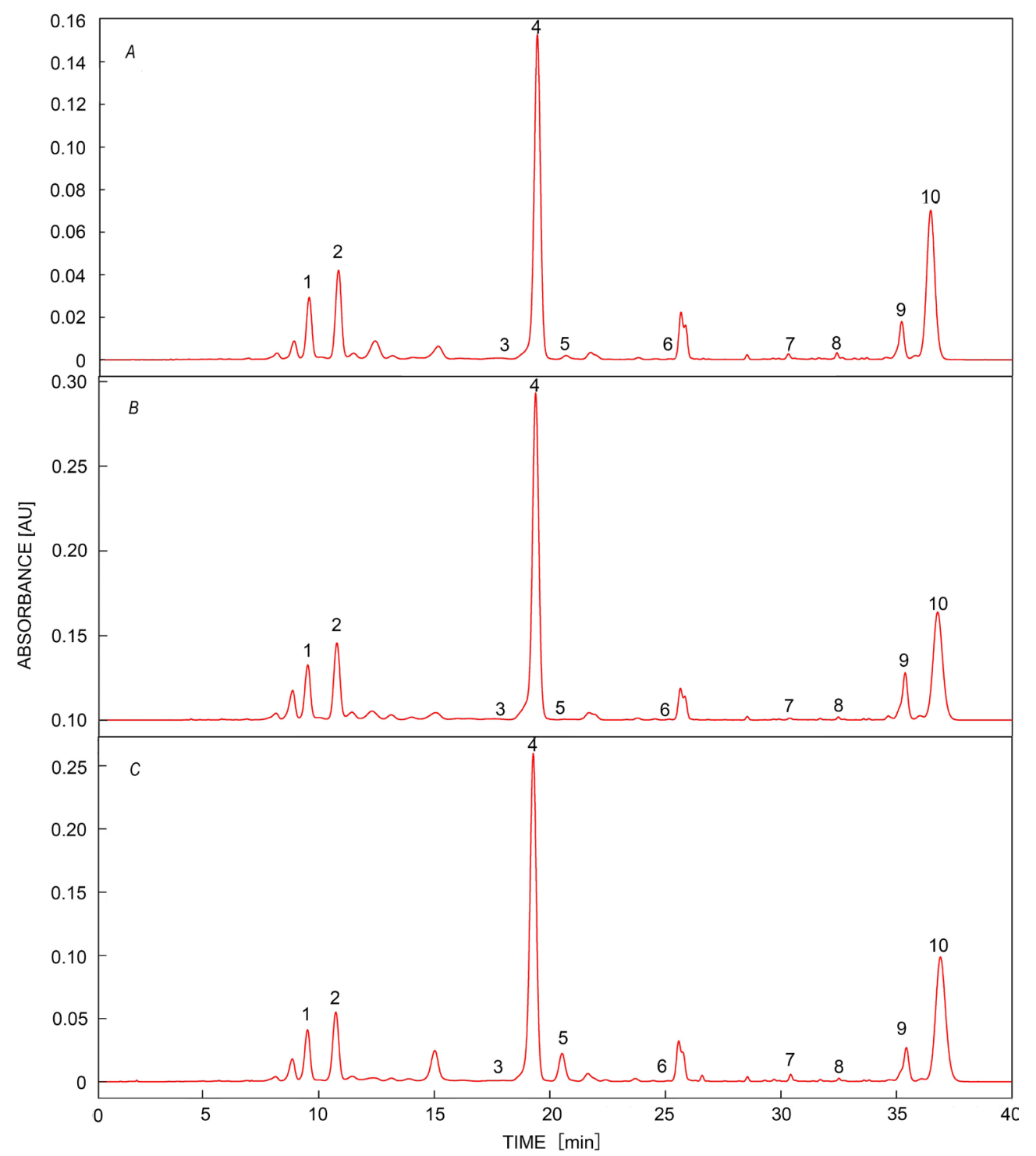

Fig. 8. Chromatograms of carotenoid compositions in $\mathrm{H} 4$ pepper leaves at $20 \mathrm{~d}$ after treatment under different treatments: $(A) \mathrm{CK}$ (normal temperature and light, $28 / 18^{\circ} \mathrm{C}$ and $300 \mu \mathrm{mol} \mathrm{m}{ }^{-2} \mathrm{~s}^{-1}$ ); (B) L (low light, $28 / 18{ }^{\circ} \mathrm{C}$ and $100 \mu \mathrm{mol} \mathrm{m}^{-2} \mathrm{~s}^{-1}$ ), and (C) LL (low temperature combined with low light, $15 / 5^{\circ} \mathrm{C}$ and $\left.100 \mu \mathrm{mol} \mathrm{m}^{-2} \mathrm{~s}^{-1}\right) .1$ - neoxanthin; 2 - violaxanthin; 3 - antheraxanthin; 4 - lutein; 5 - zeaxanthin; 6 - lutein epoxide; 7 - lycopene; 8 - phytoene; 9 - $\alpha$-carotene; and 10 - $\beta$-carotene.

(Casal 2012, Gommers et al. 2013).

Chl content is a vital index that indicates the development of chloroplast and the capacity for photosynthesis. Previous studies have reported reductions in Chl $a$, Chl $b, \mathrm{Chl}(a+b)$, and Car contents in the leaves of mini Chinese cabbage (Hu et al. 2015), sweet pepper (Sui et al. 2012), and tomato (Shu et al. 2016) under L and LL. These results are in line with our findings which may be attributed to the acceleration of Chl-degrading enzyme activity by regulation of chlorophyllase caused by stress (Bajguz and Hayat 2009). In the present study, a larger reduction in photosynthetic pigments was observed in both varieties under LL than under L (Fig. 2), suggesting that LL damaged the chloroplast structure, whereas L affected only the distribution and shape of chloroplasts and did not damage them (Ou et al. 2015).
Photosynthetic gas-exchange parameters (i.e., E, $g_{\mathrm{s}}$, $P_{\mathrm{N}}$, and $C_{\mathrm{i}}$ ) directly reflect the state of photosynthesis. The reasons for the decrease in the $P_{\mathrm{N}}$ of plants under stress include stomatal and nonstomatal factors (Shu et al. 2016). In the current study, the $E$ and $P_{\mathrm{N}}$ values of the pepper seedlings were significantly lower than those in $\mathrm{CK}$ and declined with the prolongation of the treatment time. We performed the correlation analysis between the water content and $E$; no significant correlation was found in L5 $(r=0.418, P=0.262>0.05)$, while a significant positive correlation was observed in H4 $(r=0.952$, $P=0.000<0.05)$, which means that the low water content of $\mathrm{H} 4$ plant seedlings was caused by $E$ under L and LL. On the contrary, the $C_{\mathrm{i}}$ dramatically increased (Fig. 3), indicating that the decrease in $P_{\mathrm{N}}$ was caused by nonstomatal factors. This finding is in agreement with the 
results observed for low temperature $\left(13 / 10^{\circ} \mathrm{C}\right)$, which led to a decrease in the photosynthetic rate in sorghum seedlings (Janowiak et al. 2015). Several researchers have suggested that the reason for the restriction of ribulose1,5-bisphosphate carboxylation and reduction of $P_{\mathrm{N}}$ under striking stress can be explained by the damaged photochemical reaction center and increased intercellular $\mathrm{CO}_{2}$ concentration that inhibits $\mathrm{CO}_{2}$ utilization, thus showing nonstomatal limitation (Pilon et al. 2018, Sarabi et al. 2019). However, under L, plants always exhibit stomatal limitation due to stomatal closure caused by a high abscisic acid content. Therefore, the $\mathrm{CO}_{2}$ supply is restricted. We found that the $P_{\mathrm{N}}$ and $E$ in L5 declined with decrease of $C_{\mathrm{i}}$ compared with those in CK after the 20-d treatment. This result is in agreement with that of $\mathrm{Hu}$ et al. (2015), who demonstrated that low-light-related reduction in photosynthesis is probably due to a decline in $C_{\mathrm{i}}$ and not due to the light-harvesting capacity. Furthermore, L downregulates the transcript levels of six Calvin cyclerelated genes, namely, $r b c L, r b c S, G A P D H, F B A, F B P a s e$, and $T K$, which also explains the decrease in $P_{\mathrm{N}}(\mathrm{Hu}$ et al. 2017).

Chl fluorescence is used to assess photosynthetic activity and evaluate the extent of damage to the photosynthetic apparatus. $\mathrm{F}_{\mathrm{v}} / \mathrm{F}_{\mathrm{m}}$ represents the activity of PSII. In this study, $L$ slightly increased the $F_{v} / F_{m}$, but LL decreased it in both varieties (L5 and H4). These our results disagree with the experiments where $\mathrm{F}_{\mathrm{v}} / \mathrm{F}_{\mathrm{m}}$ does not significantly change along with the leaf aging in sweet pepper under L (Sui et al. 2012), which might be likely due to the effects of different varieties and leaf ages. The $\mathrm{q}_{\mathrm{P}}$ and $\mathrm{q}_{\mathrm{L}}$ are often used in assessment of the fraction of open PSII reaction centers and reflect the photochemical quenching of electron capture in the reaction centers. In our study, L and LL caused ETR to decrease (Fig. 5; Table S2, supplement). The $\mathrm{q}_{\mathrm{P}}$ declined under L and LL in both L5 an H4. Nevertheless, higher impairments were observed under LL. These findings suggest that L and LL can decrease the open proportion of PSII reaction centers, block electron transfer, reduce PSII receptors in the electron transport chain and $\mathrm{Q}_{\mathrm{A}}$, and decrease the maximum light energy capture efficiency. $Y_{(\text {II) }}$ corresponds to the fraction of energy converted into the photochemical portion in PSII, and $\mathrm{Y}_{(\mathrm{NO})}$ corresponds to the fraction of energy that is dissipated in the form of heat and fluorescence caused by the closed PSII reaction centers. $\mathrm{Y}_{(\mathrm{NPQ})}$ reflects the fraction of energy dissipated in the form of heat via the regulated photoprotective nonphotochemical pathway. In this study, the decrease in $\mathrm{Y}_{(\mathrm{II})}$ accompanied by increases in $\mathrm{Y}_{(\mathrm{NPQ})}$ and $\mathrm{Y}_{(\mathrm{NO})}$ were observed under L and LL stresses. Additionally, a larger reduction in $\mathrm{Y}_{(\mathrm{II})}$ or an increase in $\mathrm{Y}_{(\mathrm{NPQ})}$ was found in the seedlings grown under LL compared to those grown under L. The values of $\mathrm{Y}_{(\mathrm{NO})}$ in both treatments in L5 slightly increased, but the reduction observed in $\mathrm{H} 4$ under LL was compensated by a large increase in $\mathrm{Y}_{(\mathrm{NPQ}}$ ) (Fig. 6). Previous reports have indicated that the stress generally damages the photosynthetic apparatus, resulting in an increase in

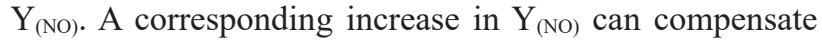
for a reduction in $\mathrm{Y}_{(\mathrm{II})}$, and a decrease in $\mathrm{Y}_{(\mathrm{II})}$ or $\mathrm{Y}_{(\mathrm{NO})}$ is quantitatively compensated for by a high $\mathrm{Y}_{(\mathrm{NPQ})}$ (Klug- hammer and Schreiber 2008).

Car are involved in plant photosynthesis and photoprotection (Kumar et al. 2013, Joubert et al. 2016). Several reports have shown that two xanthophyll cycles exist in plant bodies: one is the VAZ cycle, which is commonly present in all plants and includes Vio, Ant, and Zea that can be interconverted, and the other is the lutein epoxide ( $\mathrm{Lx}$ ) cycle (Lx-L cycle) containing lutein and lutein epoxide (Esteban and García-Plazaola 2014). Plants grown under stress exhibit photoinhibition, which results in a decrease of photosynthesis due to excessive light that cannot be used by plants and causes light damage to the photosystems. However, higher plants mitigate photoinhibition through NPQ and the heat dissipation of excitation energy in the antenna system, which is primarily dissipated via Zea (Demmig-Adams et al. 1995). Keyhaninejad et al. (2012) concluded that high light results in the accumulation of leaf carotenoids in field-grown chili peppers, especially of $\beta$-Car and other unidentified carotenoid compounds. However, in the present study, pepper seedlings responded to $\mathrm{L}$ by the significant increase in the concentrations of the six carotenoids, namely, Neo, Vio, Lut, Phy, $\alpha$-Car, and $\beta$-Car, whereas the Ant and Zea in both varieties decreased. Lut-epoxide exhibited the opposite trend in both varieties. Thayer and Björkman (1990) demonstrated that the size of the xanthophyll cycle pool $(\mathrm{V}+\mathrm{A}+\mathrm{Z})$ is four times greater in sun-grown shade-intolerant species than that in shadegrown shade-tolerant species. This finding is in agreement with our result, showing 0.67 higher VAZ pool in L5 than that in H4. However, the authors did not find any differences in the changes in Lut and Neo between the two groups and because of the larger increase in $\alpha$-Car than that in $\beta$-Car, the $\alpha$-Car $/ \beta$-Car ratio increased in the shade-grown leaves. In addition, some researchers have argued that $\alpha$-Car and Lx, belonging to the $\alpha$-branch of carotenoids, are dominant in shade environments (Demmig-Adams and Adams 1992). This result is consistent with those of our study possibly because of the upregulation of $\varepsilon$-cyclases under L (Jahns et al. 2001). Thus, plants can adjust their photosystems and photosynthetic enzymes to acclimate to long-lasting environmental stress. Our study revealed that a variation in carotenoid compounds is an effective mechanism of autoregulation, as reported by Ahn et al. (2008) and Johnson et al. (2009). The xanthophyll cycle (involving Vio, Ant, and Zea) and the Lx-L cycle are included in numerous models of NPQ and have the function of energy dissipation.

In our study, severe inhibition of plant growth, photosynthetic capacity, photosynthetic gas exchange, and Chl fluorescence was observed under LL. Among the ten kinds of carotenoids, Neo, Vio, Lut, Zea, $\alpha$-Car, and $\beta$-Car were significantly accumulated in both varieties after 20 d. Overall, carotenoids can deactivate ${ }^{1} \mathrm{O}_{2}$ produced under $\mathrm{L}$ and LL to the ground state and then gain excessive energy to an excited state, and finally release the energy into the environment to reach the initial state (Stahl and Sies 2003). Lut was the predominant component in all treatments regardless of light or temperature (44.51$\left.128.72 \mu \mathrm{g} \mathrm{g}^{-1}\right)$, and Ant was the least abundant (0.05-0.61 $\left.\mu \mathrm{g} \mathrm{g}^{-1}\right)$. Notably, $\alpha$-carotene significantly changed for 
90-210\% upon exposure to L and played an important role under L. Zea was significantly (6.69-8.88 times) higher under LL than under CK. Leaf carotenoids present in the chloroplasts in the form of chlorophyll-carotenoidprotein complexes function as antennae to harvest light for photosynthesis and eliminate reactive oxygen species (i.e., $\mathrm{O}_{2}^{-}, \mathrm{H}_{2} \mathrm{O}_{2}, \mathrm{OH}^{-}$, and ${ }^{1} \mathrm{O}_{2}$ ) accumulated under stressful conditions by participating in oxygen action with carotenoids (Hu et al. 2010, Havaux 2014, Li et al. 2015). Carotenoids participating in transferring excitation energy and deactivating thermal energy are considered the first line of defense against singlet oxygen toxicity (Ramel et al. 2012). Early studies have indicated that ${ }^{1} \mathrm{O}_{2}$ can be scavenged by a series of chemical reactions involving the reduction of $\beta$-Car and Lut into aldehydes and $\beta$-carotene endoperoxide (Ramel et al. 2012). In addition, high amounts of Zea probably contribute to the deepoxidation of Vio to Zea (Saini and Keum 2018). Therefore, $\beta$-Car and Zea accumulate rapidly. Differently, $\alpha$-Car increased under L, which may be the result of high expression of $L C Y-\varepsilon$, which modulates carotenoid biosynthesis toward the $\alpha$-Car branch (Saini and Keum 2018).

Conclusions: Our study showed that L and LL caused the reductions in plant growth and photosynthesis capacity, while greater inhibitions were observed under LL. Moreover, carotenoid-related metabolic compounds accumulated in pepper (Capsicum annuиm L.) showed different response to stresses. Zea increased dramatically in our study, which may enhance LL tolerance. The higher amounts of Zea probably result from deepoxidation of Vio to Zea (Saini and Keum 2018), and consume the excess light energy leading to the protection of photosynthetic organs and elimination of reactive oxygen species. Moreover, $\alpha$-Car significantly increased under L, which improved plants resistance. This increase is probably a result of high expression of $L C Y-\varepsilon$, which modulates carotenoid biosynthesis toward the $\alpha$-Car branch (Saini and Keum 2018). In conclusion, the protective carotenoid compositions in pepper leaves varied to avoid severe damage and promote acclimation to LL and L.

\section{References}

Ahn T.K., Avenson T.J., Ballottari M. et al.: Architecture of a charge-transfer state regulating light harvesting in a plant antenna protein. - Science 320: 794-797, 2008.

Arena C., Vitale L.: Chilling-induced reduction of photosynthesis is mitigated by exposure to elevated $\mathrm{CO}_{2}$ concentrations. Photosynthetica 56: 1259-1267, 2018.

Bajguz A., Hayat S.: Effects of brassinosteroids on the plant responses to environmental stresses. - Plant Physiol. Bioch. 47: 1-8, 2009.

Barrero-Gil J., Huertas R., Rambla J.L. et al:: Tomato plants increase their tolerance to low temperature in a chilling acclimation process entailing comprehensive transcriptional and metabolic adjustments. - Plant Cell Environ. 39: 23032318, 2016.

Bowen-O'Connor C.A., VanLeeuwen D.M., Bettmann G. et al.: Variation in violaxanthin and lutein cycle components in two provenances of Acer grandidentatum L. exposed to contrasting light. - Acta Physiol. Plant. 35: 541-548, 2013.

Caliandro R., Nagel K.A., Kastenholz B. et al.: Effects of altered $\alpha$ - and $\beta$-branch carotenoid biosynthesis on photoprotection and whole-plant acclimation of Arabidopsis to photooxidative stress. - Plant Cell Environ. 36: 438-453, 2013.

Cao Y., Luo Q., Tian Y., Meng F.: Physiological and proteomic analyses of the drought stress response in Amygdalus mira (Koehne) Yü et Lu roots. - BMC Plant Biol. 17: 53, 2017.

Casal J.J.: Shade avoidance. - Arabidopsis Book 10: e0157, 2012.

Daood H.G., Biacs P.A.: Simultaneous determination of Sudan dyes and carotenoids in red pepper and tomato products by HPLC. - J. Chromatogr. Sci. 43: 461-465, 2005.

Demmig-Adams B., Adams III W.W.: Carotenoid composition in sun and shade leaves of plants with different life forms. Plant Cell Environ. 15: 411-419, 1992.

Demmig-Adams B., Adams III W.W.: Photoprotection in an ecological context: The remarkable complexity of thermal energy dissipation. - New Phytol. 172: 11-21, 2006.

Demmig-Adams B., Adams III. W.W., Logan B.A., Verhoeven A.S.: Xanthophyll cycle-dependent energy dissipation and flexible photosystem II efficiency in plants acclimated to light stress. - Aust. J. Plant Physiol. 22: 249-260, 1995.

Enfissi E.M.A., Nogueira M., Bramley P.M., Fraser P.D.: The regulation of carotenoid formation in tomato fruit. - Plant J. 89: 774-788, 2017.

Esteban R., García-Plazaola J.I.: Involvement of a second xanthophyll cycle in non-photochemical quenching of chlorophyll fluorescence: The lutein epoxide story. - In: DemmigAdams B., Garab G., Adams III W.W., Govindjee (ed.): Non-Photochemical Quenching and Energy Dissipation in Plants, Algae and Cyanobacteria. Advances in Photosynthesis and Respiration. Vol. 40. Pp. 277-295. Springer, Dordrecht 2014.

Franklin K.A.: Shade avoidance. - New Phytol. 179: 930-944, 2008.

Franklin K.A., Toledo-Ortiz G., Pyott D.E., Halliday K.J.: Interaction of light and temperature signalling. - J. Exp. Bot. 65: 2859-2871, 2014.

Giacalone G., Chiabrando V., Bardi L.: Changes in nutritional properties of minimally processed fresh fruit during storage. Ital. J. Food Sci. 22: 307-314, 2010.

Gommers C.M., Visser E.J., St Onge K.R. et al.: Shade tolerance: when growing tall is not an option. - Trends Plant Sci. 18: 65-71, 2013.

Greer D.H., Weedon M.M.: Interactions between light and growing season temperatures on growth and development and gas exchange of Semillon (Vitis vinifera L.) vines grown in an irrigated vineyard. - Plant Physiol. Bioch. 54: 59-69, 2012.

Guzman I., Hamby S., Romero J. et al.: Variability of carotenoid biosynthesis in orange colored Capsicum spp. - Plant Sci. 179: 49-59, 2010.

Havaux M.: Carotenoid oxidation products as stress signals in plants. - Plant J. 79: 597-606, 2014.

Hikosaka K., Ishikawa K., Borjigidai A. et al.: Temperature acclimation of photosynthesis: mechanisms involved in the changes in temperature dependence of photosynthetic rate. J. Exp. Bot. 57: 291-302, 2006.

Hu L., Liao W., Dawuda M.M. et al.: Appropriate $\mathrm{NH}_{4}{ }^{+}: \mathrm{NO}_{3}{ }^{-}$ ratio improves low light tolerance of mini Chinese cabbage seedlings. - BMC Plant Biol. 17: 22-35, 2017.

$\mathrm{Hu}$ L., Yu J., Liao W. et al.: Moderate ammonium:nitrate alleviates low light intensity stress in mini Chinese cabbage seedling by regulating root architecture and photosynthesis. Sci. Hortic.-Amsterdam 186: 143-153, 2015.

$\mathrm{Hu}$ W., Wu Y., Zeng J. et al.: Chill-induced inhibition of 
photosynthesis was alleviated by 24-epibrassinolide pretreatment in cucumber during chilling and subsequent recovery. - Photosynthetica 48: 537-544, 2010.

Jahns P., Wehner A., Paulsen H., Hobe S.: De-epoxidation of violaxanthin after reconstitution into different carotenoid binding sites of light-harvesting complex II. - J. Biol. Chem. 276: 22154-22159, 2001.

Janowiak F., Kaczanowska K., Jing H.C. et al.: Metabolic limitations to photosynthetic efficiency of sorghum seedling leaves at low temperature. - Procedia Environ. Sci. 29: 277278, 2015.

Johnson M.P., Pérez-Bueno M.L., Zia A. et al.: The zeaxanthinindependent and zeaxanthin-dependent $\mathrm{qE}$ components of nonphotochemical quenching involve common conformational changes within the photosystem II antenna in Arabidopsis. - Plant Physiol. 149: 1061-1075, 2009.

Joubert C., Young P.R., Eyéghé-Bickong H.A. et al.: Fieldgrown grapevine berries use carotenoids and the associated xanthophyll cycles to acclimate to UV exposure differentially in high and low light (shade) conditions. - Front. Plant Sci. 7: 786, 2016.

Kami C., Lorrain S., Hornitschek P., Fankhauser C.: Lightregulated plant growth and development. - Curr. Top. Dev. Biol. 91: 29-66, 2010.

Keyhaninejad N., Richins R.D., O'Connell M.A.: Carotenoid content in field grown versus greenhouse grown peppers: different responses in leaf and fruit. - Am. Soc. Hortic. Sci. 47: 852-855, 2012.

Klughammer C., Schreiber U.: Complementary PS II quantum yields calculated from simple fluorescence parameters measured by PAM fluorometry and the Saturation Pulse method. - PAM Application Notes 1: 27-35, 2008.

Kramer D.M., Johnson G., Kiirats O., Edwards G.E.: New fluorescence parameters for the determination of $\mathrm{Q}_{\mathrm{A}}$ redox state and excitation energy fluxes. - Photosynth. Res. 79: 209-218, 2004.

Krause G.H., Weis E.: Chlorophyll fluorescence and photosynthesis: The basics. - Annu. Rev. Plant Phys. 42: 313-349, 2003.

Kumar S., Sairam R.K., Prabhu K.V.: Physiological traits for high temperature stress tolerance in Brassica juncea. - Indian J. Plant Physi. 18: 89-93, 2013.

Li J., Xie J., Yu J. et al.: Reversed-phase high-performance liquid chromatography for the quantification and optimization for extracting 10 kinds of carotenoids in pepper (Capsicum annuum L.) leaves. - J. Agr. Food Chem. 65: 8475-8488, 2017.

Li J., Yang P., Gan Y. et al.: Brassinosteroid alleviates chillinginduced oxidative stress in pepper by enhancing antioxidation systems and maintenance of photosystem II. - Acta Physiol. Plant. 37: 222, 2015.

Lu T., Yu H., Li Q. et al.: Improving plant growth and alleviating photosynthetic inhibition and oxidative stress from lowlight stress with exogenous GR24 in tomato (Solanum lycopersicum L.) seedlings. - Front. Plant Sci. 10: 490, 2019.

McElroy J.S., Kopsell D.A., Sorochan J.C., Sams C.E.: Response of creeping bentgrass carotenoid composition to high and low irradiance. - Crop Sci. 46: 2606-2612, 2006.

McLeod M.J., Guttman S.I., Eshbaugh W.H.: Early evolution of chili peppers (Capsicum). - Econ. Bot. 36: 361-368, 1982.

Megha S., Basu U., Kav N.N.V.: Regulation of low temperature stress in plants by microRNAs. - Plant Cell Environ. 41: 1-15, 2018.

Ogweno J.O., Song X.S., Hu W.H. et al.: Detached leaves of tomato differ in their photosynthetic physiological response to moderate high and low temperature stress. - Sci. Hortic.-
Amsterdam 123: 17-22, 2009.

Ou L., Wei G., Zhang Z. et al.: Effects of low temperature a nd low irradiance on the physiological characteristics and related gene expression of different pepper species. Photosynthetica 53: 85-94, 2015.

Page V., Blösch R.M., Feller U.: Regulation of shoot growth, root development and manganese allocation in wheat (Triticum aestivum) genotypes by light intensity. - Plant Growth Regul. 67: 209-215, 2012.

Parida A.K., Veerabathini S.K., Kumari A., Agarwal P.K.: Physiological, anatomical and metabolic implications of salt tolerance in the halophyte Salvadora persica under hydroponic culture condition. - Front. Plant Sci. 7: 351, 2016.

Pengelly J.J.L., Sirault X.R.R., Tazoe Y., von Caemmerer S.: Growth of the $\mathrm{C}_{4}$ dicot Flaveria bidentis: Photosynthetic acclimation to low light through shifts in leaf anatomy and biochemistry. - J. Exp. Bot. 61: 4109-4122, 2010.

Perkins-Veazie P., Collins J.K., Davis A.R., Roberts W.: Carotenoid content of 50 watermelon cultivars. - J. Agr. Food Chem. 54: 2593-2597, 2006.

Pilon C., Snider J.L., Sobolev V. et al.: Assessing stomatal and non-stomatal limitations to carbon assimilation under progressive drought in peanut (Arachis hypogaea L.). - J. Plant Physiol. 231: 124-134, 2018.

Ramel F., Birtic S., Cuiné S. et al.: Chemical quenching of singlet oxygen by carotenoids in plants. - Plant Physiol. 158: 1267-1278, 2012.

Ruelland E., Vaultier M.N., Zachowski A., Hurry V.: Cold signalling and cold acclimation in plants. - Adv. Bot. Res. 49: 35-150, 2009.

Sáez P.L., Cavieres L.A., Galmés J. et al.: In situ warming in the Antarctic: Effects on growth and photosynthesis in Antarctic vascular plants. - New Phytol. 218: 1406-1418, 2018.

Sahoo M.R., Dasgupta M., Kole P.C., Mukherjee A.: Photosynthetic, physiological and biochemical events associated with polyethylene glycol-mediated osmotic stress tolerance in taro (Colocasia esculenta L. Schott). - Photosynthetica 56: 10691080, 2018.

Saini R.K., Keum Y.S.: Significance of genetic, environmental, and pre- and postharvest factors affecting carotenoid contents in crops: A review. - J. Agr. Food Chem. 66: 5310-5324, 2018.

Sarabi B., Fresneau C., Ghaderi N. et al.: Stomatal and nonstomatal limitations are responsible in down-regulation of photosynthesis in melon plants grown under the saline condition: Application of carbon isotope discrimination as a reliable proxy. - Plant Physiol. Bioch. 141: 1-19, 2019.

Semeniuk P., Moline H.E., Abbott J.A.: A comparison of the effects of $\mathrm{ABA}$ and an antitranspirant on chilling injury of coleus, cucumbers, and Dieffenbachia. - J. Am. Soc. Hortic. Sci. 111: 241-257, 1986.

Serrano M., Zapata P.J., Castillo S.: Antioxidant and nutritive constituents during sweet pepper development and ripening are enhanced by nitrophenolate treatments. - Food Chem. 118: 497-503, 2010.

Seyfabadi J., Ramezanpour Z., Khoeyi Z.A.: Protein, fatty acid, and pigment content of Chlorella vulgaris under different light regimes. - J. Appl. Phycol. 23: 721-726, 2011.

Shu S., Tang Y., Yuan Y. et al.: The role of 24-epibrassinolide in the regulation of photosynthetic characteristics and nitrogen etabolism of tomato seedlings under a combined low temperature and weak light stress. - Plant Physiol. Bioch. 107: 344-353, 2016.

Sies H., Stahl W.: Vitamins E and C, beta-carotene, and other carotenoids as antioxidants. - Am. J. Clin. Nutr. 62: 1315S-1321S, 1995.

Skupień J., Wójtowicz J., Kowalewska Ł. et al.: Dark- 
chilling induces substantial structural changes and modifies galactolipid and carotenoid composition during chloroplast biogenesis in cucumber (Cucumis sativus L.) cotyledons. Plant Physiol. Bioch. 111: 107-118, 2016.

Stahl W., Sies H.: Antioxidant activity of carotenoids. - Mol. Aspects Med. 24: 345-351, 2003.

Sui X.L., Mao S.L., Wang L.H. et al.: Effect of low light on the characteristics of photosynthesis and chlorophyll $a$ fluorescence during leaf development of sweet pepper. J. Integr. Agr. 11: 1633-1643, 2012.

Tattini M., Remorini D., Pinelli P. et al.: Morpho-anatomical, physiological and biochemical adjustments in response to root zone salinity stress and high solar radiation in two Mediterranean evergreen shrubs, Myrtus communis and Pistacia lentiscus. - New Phytol. 170: 779-794, 2006.

Thayer S.S., Björkman O.: Leaf xanthophyll content and composition in sun and shade determined by HPLC. Photosynth. Res. 23: 331-343, 1990.
Wahyuni Y., Ballester A.R., Sudarmonowati E. et al.: Metabolite biodiversity in pepper (Capsicum) fruits of thirty-two diverse accessions: variation in health-related compounds and implications for breeding. - Phytochemistry 72: 1358-1370, 2011.

Xie J., Yu J., Huang G. et al.: [Relationship between carotenoid content and low-light tolerance or chilling and low-light tolerance of pepper varieties.] - Sci. Agr. Sin. 43: 4036-4044, 2010. [In Chinese]

Yu H., Zhao W., Wang M. et al.: The exogenous application of spermidine alleviates photosynthetic inhibition and membrane lipid peroxidation under low-light stress in tomato (Lycopersicon esculentum Mill.) seedlings. - Plant Growth Regul. 78: 413-420, 2016.

Zhu H., Li X., Zhai W. et al.: Effects of low light on photosynthetic properties, antioxidant enzyme activity, and anthocyanin accumulation in purple pak-choi (Brassica campestris ssp. chinensis Makino). - PLoS ONE 12: e0179305, 2017.

(C) The authors. This is an open access article distributed under the terms of the Creative Commons BY-NC-ND Licence. 